\title{
The Effects of Confinement on Sleep Quality and Level of Interest in University Students [Letter]
}

\author{
Muhammad Zakwan Zakariya \\ Jie Man Low iD
}

School of Medical Sciences, University of Manchester, Manchester, UK
This article was published in the following Dove Press journal:

Nature and Science of Sleep

\section{Dear editor}

We would like to comment on the recent cross-sectional study by Martínez-Lezaun et $\mathrm{al}^{1}$ regarding the impact of confinement due to COVID-19 on the quality of sleep and interests of students across different Spanish universities. The authors concluded that confinement is associated with worsened quality of sleep and reduced activity. As medical undergraduates ourselves, we have personally observed the high prevalence of this matter being discussed in community-based settings (GP practices) in the UK. We recognize the importance of good sleep hygiene and we strongly resonate with the study participants with regards to how the lockdown can negatively affect health and sleep. The authors have enlightened us with useful insights into this topic of interest; however, we would like to address several issues, in hopes of informing future research in this area of study.

Firstly, potential confounders including the effects of unfavorable living conditions and lower socioeconomic status, ${ }^{2}$ both of which could have been precipitated by confinement, were not adequately addressed in this study. Other lifestyle factors might have also played a role in the deterioration of sleep quality. Examples of such factors include smoking, alcohol and caffeine consumption, as suggested by Fischer et al. ${ }^{3}$ Additionally, as the participants were recruited across different years of study, there would have been an inherent variation in academic commitments, which in and of itself might have pre-determined their quality of sleep. This echoes with the findings of a study by Rezaei et $\mathrm{al}^{4}$ which reported poorer sleep quality in students of later year groups. Thus, future studies may benefit from recruiting a more homogeneous study population (ie limiting participants to one year group).

Furthermore, this study employed two seemingly arbitrary time intervals (ie 20 and 40 days) during which the sleep quality and interests in activity were assessed. We are curious as to why these specific intervals were utilized, and their significance in determining how much the students' sleep quality and interests have changed preand mid-confinement. The authors aptly noted the lack of statistically significant differences when comparing the sleep quality between these two timepoints (M2 and M3). We suggest lengthening the window of time from 20 days to one month, considering the latter has been used as the reference period for the Pittsburgh Sleep Quality Index. ${ }^{5}$

In summary, the authors have prudently elucidated the undesirable repercussions on the quality of sleep and interests in activities among university students due to confinement during COVID-19. This study necessitates further exploration into solutions that
Correspondence: Muhammad Zakwan Zakariya; Jie Man Low

School of Medical Sciences, University of Manchester, Manchester, UK

Email muhammad.zakariya-2@student. manchester.ac.uk; jieman.low@student. manchester.ac.uk 
can promote sleep hygiene amidst this pandemic, in hopes of improving the wellbeing of university students.

\section{Disclosure}

The authors report no conflicts of interest for this communication.

\section{References}

1. Martínez-Lezaun I, Santamaría-Vázquez M, Del Líbano M. Influence of confinement by COVID-19 on the quality of sleep and the interests of university students. Nat Sci Sleep. 2020;12:1075-1081. doi:10.21 47/NSS.S280892
2. Johnson DA, Billings ME, Hale L. Environmental determinants of insufficient sleep and sleep disorders: implications for population health. Curr Epidemiol Rep. 2018;5(2):61-69. doi:10.1007/s40471-018-0139-y

3. Fischer FM, Nagai R, Teixeira LR. Explaining sleep duration in adolescents: the impact of socio-demographic and lifestyle factors and working status. Chronobiol Int. 2008;25(2-3):359-372. doi:10.1080/07420520802110639

4. Rezaei M, Khormali M, Akbarpour S, Sadeghniiat-Hagighi K, Shamsipour M. Sleep quality and its association with psychological distress and sleep hygiene: a cross-sectional study among pre-clinical medical students. Sleep Sci. 2018;11(4):274-280. doi:10.5935/19840063.20180043

5. Buysse DJ, Reynolds CF 3rd, Monk TH, Berman SR, Kupfer DJ. The Pittsburgh sleep quality index: a new instrument for psychiatric practice and research. Psychiatry Res. 1989;28(2):193-213. doi:10.1016/0165-1781(89)90047-4

Dove Medical Press encourages responsible, free and frank academic debate. The content of the Nature and Science of Sleep 'letters to the editor' section does not necessarily represent the views of Dove Medical Press, its officers, agents, employees, related entities or the Nature and Science of Sleep editors. While all reasonable steps have been taken to confirm the content of each letter, Dove Medical Press accepts no liability in respect of the content of any letter, nor is it responsible for the content and accuracy of any letter to the editor.

Nature and Science of Sleep

\section{Dovepress}

\section{Publish your work in this journal}

Nature and Science of Sleep is an international, peer-reviewed, open access journal covering all aspects of sleep science and sleep medicine, including the neurophysiology and functions of sleep, the genetics of sleep, sleep and society, biological rhythms, dreaming, sleep disorders and therapy, and strategies to optimize healthy sleep.
The manuscript management system is completely online and includes a very quick and fair peer-review system, which is all easy to use. Visit http://www.dovepress.com/testimonials.php to read real quotes from published authors. 